\title{
A Survival Approach to Prediction of Default Drivers for Indian Listed Companies
}

\author{
Vandana Gupta \\ Finance, Fore School of Management, New Delhi, India \\ Email: vandana@fsm.ac.in
}

How to cite this paper: Gupta, V. (2017) A Survival Approach to Prediction of Default Drivers for Indian Listed Companies. Theoretical Economics Letters, 7, 116-138. https://doi.org/10.4236/tel.2017.72011

Received: November 29, 2016

Accepted: February 1, 2017

Published: February 4, 2017

Copyright $\odot 2017$ by author and Scientific Research Publishing Inc. This work is licensed under the Creative Commons Attribution International License (CC BY 4.0).

http://creativecommons.org/licenses/by/4.0/

(c) (i) Open Access

\begin{abstract}
The objective of the research study is to identify the key predictors that can explain default risk for Indian listed companies using survival analysis. The author has applied the semi-parametric Cox proportional hazard model to test the impact of financial ratios, capital market ratios, macro-economic variables, size and age of companies, and the ownership structure of promoters to a dataset of 859 companies panning across 10 sectors. Unlike traditional models on default prediction, survival models focus on "time to default" as the dependent variable. The empirical findings reveal that return on capital employed (ROCE), return on net worth (ROE), interest coverage ratio, exchange rate volatility, GDP growth rate, stock index, promoters holdings \% and the percent of shares pledged are all significant predictors of default. Among the market variables, it is seen that beta and the ratio of market value of equity/book value of debt are statistically significant variables in explaining default risk. The empirical findings also generate the hazard ratio for each covariate which examines the predicted change in the hazard for a unit increase in the predictor. The author extends the research by applying the marketbased KMV structural model to obtain continuous observations of default probability and regressing the same against all the ${ }^{1}$ covariates (Gupta et al., 2013) [1]. It is observed that the set of significant covariates are almost common to those generated by our survival approach. The study concludes in emphasizing the significance of survival models in default prediction as unlike traditional accounting-based and market-based models, these models assess relationship between survival time and covariates. The application of survival models is strongly recommended for credit risk evaluation and modeling as structuring of loans can be done by lenders by assessing the survival times of different firms across the entire observation period being considered.
\end{abstract}

${ }^{1}$ The author is thankful to the editor and referees for their valuable inputs and feedback. 


\section{Keywords}

Default Prediction, Survival Analysis, Cox Proportional Hazard, KMV, Credit Risk

\section{Introduction}

Credit risk is among the four business risks (capital risk, market risk, credit risk and operational risk) faced by organizations. The last decade or so has witnessed a growing emphasis on management and measurement of this risk. This has been largely an outcome of the implementation of Basel norms with their thrust on generating internal rating-based models (IRB): the exponential growth in markets for derivatives and the growth in innovative techniques of risk management. Credit risk in the simplest way may be defined as the "probability of loss from a credit transaction". An integral element of credit risk is the risk of default, that is, failure to meet debt obligations. Companies are essentially said to be in financial distress when they are unable to service debt, both the interest component and also the repayments. A prolonged state of financial distress leads to liquidation and bankruptcy. While banks have their internal credit risk models to assess creditworthiness of corporates before lending, in the traditional sense, credit rating agencies have been playing a pivotal role in assigning a rating which is an indication of the corporate's credit quality. Rating is a symbol that denotes how sound a company is in meeting its contractual obligations of debt. The role of rating agencies is prominent from the perspective of issuers of debt (borrowers) as a high rating lowers the cost of raising debt. Credit Rating Agencies (CRAs) thus, also, impart some degree of protection to investors against default by the symbol they assign to the debt instrument. While ratings serve the entire gamut of issuers, investors and regulators, they came under a cloud after the sub-prime crisis. Some of the limitations of CRAs came to light include their dual role of acting on behalf of both issuers and investors, conflict of interest, confidentiality of rating reports among others. Moreover, ratings are ordinal in nature, they are non-quantifiable. Within a rating symbol, there is a wide spectrum of companies whose probability of survival or default maybe different, but they are indicated by the same symbol.

In India, rating agencies have been the predominant source of measuring creditworthiness for corporates. However, in the recent past, limitations of rating agencies combined with increasing significance of quantitative models have led to academic work in Indian context to examine and suggest improvements in the process and methodology adopted by credit rating agencies (CRAs).

Banks in India have been facing rising non-performing assets (NPA), which further substantiates the need for credit risk models that are proactive in predicting financial distress. Some of the steps taken by the Indian central bank, the Reserve Bank of India (RBI) include declaring financially distressed corporates under CDR (corporate debt restructuring) scheme wherein a consortium of banks 
restructures the existing debt to make it easier for the firm to service the debt. A step further in this direction is the strategic debt restructuring (SDR) scheme where banks gain equity stake in the distressed company. SDR is usually a follow of the CDR, when firms continue to falter in their payments. While these steps have paved the way for minimizing credit risk and lowering NPAs, the absence of a bankruptcy law, (the insolvency and bankruptcy code is still in nascent stage) warrants timely prediction of financial distress and thus provide warning to lenders against impending insolvency. This can also lead to effective monitoring of the financial health of banks, institutions and funds by regulators by anticipating the degree of financial distress risk associated with them. Early prediction of default risk enables practitioners to use probability default forecasts to price corporate debt and for internal rating based approach for Basel norms. Academicians use bankruptcy forecasts to test various hypotheses that default risk is priced in stock return.

Some of the potential relevance of determining credit risk can be studied by using various statistical and other models as has been advocated in research in other countries. Traditionally the credit risk literature has taken two approaches to measure default on debt. One is the structural approach which is based on market variables, and the second is the statistical approach or the reduced approach which factors in information from the financial statements. Though there is vast literature on credit risk models, with works on accounting-based and market-based models, these models focus on static modeling using cross-sectional data. Prior researchers only choose to use one period observation with a single-period logistic regression or discriminant analysis. Although these methods have contributed significantly to the literature on default prediction, they have not considered "time to failure" which is an integral factor in corporate distress analysis. This factor is considered in survival models. In survival analysis many different regression modeling strategies can be applied to predict the risk of future events. Survival analysis will typically address the question: When will the event occur?

The origin of survival models is traced in the medical science and these models have gradually been applied even in the field of bankruptcy prediction. These models allow a firm's risk of bankruptcy to change over time, measuring the likelihood of a firm to fail given the time survived and a set of explanatory variables. This technique is ideally suited to introducing a time dimension into financial distress prediction since the objective is to estimate $S(t)=P(T>t)$, the probability that financial distress will occur at a time $T$ which lies beyond the time horizon $t$, for a range of values of $t$.

It is against this backdrop that the objective of the present study is to use the survival analysis approach to examine the time to default as the dependent variable and to evaluate the predictors on a dataset of Indian listed companies. The credit risk model proposed in the research study attempts to quantify the credit risk using both accounting information as also the market variables. The criterion variable in survival analysis is the "Status" variable. In this case, the two 
possible outcomes are: defaulted (1) vs. solvent (0). For the purpose of the research study, companies are said to be under financial distress when they are given rating " $D$ " by the CRA or are under the BIFR (Bureau of Industrial and Financial Restructuring). Time to default is determined from the time of origin (year 2000) to the time of default. The author has identified accounting ratios, macro-economic variables, corporate governance parameters and market variables to test their significance in default prediction. For this purpose, the semi-parametric Cox regression has been applied. This Cox model is termed semi-parametric because while the baseline hazard can take any form, the covariates enter the model through the linear predictors. The independent variables are lagged by three years from the time of rating.

The author has extended the works of structural-based KMV model by using the continuous observations of default probability obtained and regressing against the independent variables, to identify the key predictors common to both the models.

In order to present this research work in a lucid manner, the paper has been divided into five sections. Section 2 reviews existing literature and Section 3 explains the research methodology. The empirical findings and discussion are presented in Section 4 and Section 5 is the conclusion of the study.

\section{Review of Literature}

The earliest and most-cited papers in the corporate failure literature are accounting-based models and the pioneers for these were Beaver [2], Altman [3], Ohlson [4], and Zmijewski [5]. The emphasis in the first two works was on univariate and multivariate discriminant analysis respectively. Ohlson (1980) employed a parametric approach (a conditional logit model) to predict bankruptcy in U.S. firms while Zmijewski applied the probit model. The main limitation of the models developed, namely DA, logit and probit is that they are all cross-sectional models which assume a static state of failure. Research approach was based on one period observation with a single-period logistic regression or discriminant analysis.

The market-based structural models are based on the Black-Scholes and Merton's [6] Distance to Default followed by Kealhofer, McQuown, and Vasicek [7]; herein after KMV (2003) who developed a model to determine the probability of default and named it as expected default frequency (EDF). Several variations and extensions have been made to this basic model. Some of these are: Black and Cox (1976) [8]; Longstaff and Schwartz (1995) [9]; Brockman and Turtle (2003) [10]; Bandopadhyay (2007) [11]; Baninoe (2010) [12]; Laitinen (2010) [13]; Antonio et al. (2012) [14]; and Kumar and Kumar (2012) [15].

Jensen and Meckling (1976) [16] and Shleifer and Vishny (1986, 1997) [17] conducted research on the impact of ownership patterns on default. They opined that larger institutional shareholding leads to more efficient management. $\mathrm{Xu}$ and Wang [18] did research on the relation of ownership pattern on financial performance of listed companies in China. 
The basic survival model examines the length of time before an event occurs or the time interval between the events within some observation period. The model is based on the survival time or the hazard rate as the dependent variable. In a context of default, the objective is to quantify the relationship between survival time and a set of explanatory variables. In continuous time survival analysis, the proportional hazards model (Cox, 1972) [19] is the most popular covariate effect model. The partial likelihood estimator for the proportional hazards model is studied in Breslow [20], Cox [21] and Effron [22]. The concept of survival analysis for credit scoring was pioneered by Narain [23] and extended further by Thomas et al. [24]. Narain (1992) applied the accelerated failure time (AFT) model to personal loan data. He recommended survival analysis over multiple regression for decisions relating to credits. The introduction to survival analysis for credit risk modeling was made by Thomas.

Lando [25] introduced a proportional hazards survival-analysis model to estimate the time until a bond defaults, emphasizing on economic variables as relevant covariates. In his introduction to survival analysis, Harrell [26] emphasized that survival analysis is used to analyze data in which the time until the event is of interest; if the time until the occurrence of the event were unimportant, the event could be analyzed as a binary outcome using logistic regression. Stepanova and Thomas [27] examined ways to improve the performance of the Cox proportional hazards model in credit scoring. One of the proposed improvements was to allow a decrease or increase in the effect of a covariate on the predicted time-to-failure as the loan evolves. Chava and Jarrow [28] tested the forecasting accuracy of bankruptcy hazard rate models for US companies from 1962 to 1999. Laitinen [29] used survival analysis to model the duration of time that preceded a firm's initial payment default using financial ratios, size, industry and age as covariates to model the survival process using proportional hazard model. In the research study by Hou-Ou Yang et al. [30], business models were constructed for financial distress using Cox regression on a sample of Taiwanese companies. Seven models were analyzed for the impact of ratios, earnings management index and corporate governance on financial distress. The Cox proportional hazards model was also used for bankruptcy prediction in Duffie et al. [31]. T. Bellotti and J. Crook [32]) in their research reported an application of survival analysis to model default on a large data set of credit card accounts. They explored the hypothesis that probability of default (PD) is affected by general conditions in the economy over time. Lee [33] examined the usefulness of traditional financial ratios and market variables as predictors of the probability of business failure to a given time on a sample of companies listed on Taiwan Stock Exchange using the Cox proportional hazard model. Other studies using the hazard function were those of Rommer [34], Chanchrat et al. [35], Kim and Parkington [36], Nieddu and Vitiello [37].

Bulk of research on default prediction is done by focusing on accountingbased and market-based models. Accounting based models, in themselves are inflexible, backward looking and incorporate information in financial statements 
which are based on historical past. At best, the information can be updated quarterly. Structural models are forward looking, and being mathematical the probability of default can be directly computed. While market-based models can compute continuous valuations of the probability of default (PD) unlike rating agencies; to make the probability of default more exhaustive, it is important to factor in the information provided in the financial statements. However, these models are static in nature, are unable to factor time-varying covariates and do not factor time to event which is the focus of survival models.

It is also observed from the review of literature above that there has been considerable research using proportional hazard Cox regression to identify predictors to aid in bankruptcy prediction internationally. Despite numerous credit risk models available, prior works on examining survival analysis technique to bankruptcy prediction has been negligible in the Indian context. It is against this backdrop that the author has identified this gap and applied Cox regression to study the impact of financial ratios, macro-economic variables, size and age of companies, ownership pattern and market-related variables to test their significance in predicting financial distress.

The purpose of using survival model is to build a robust framework that enables banks and financial institutions in an emerging market economy like India to classify a firm in the default or non-default category based on the survival time of each firm and this can serve as a useful tool for quick evaluation of the risk profile of a corporate.

\section{Research Methodology}

\subsection{Survival Analysis}

A survival analysis (SA) technique is the term applied to a dynamic statistical tool used to analysis the time till a certain event. Survival analysis, addresses the question: When will the event occur?

SA uses the Cox proportional hazard model to analysis survival probability and failure times. The basic survival model examines the length of time before an event occurs or the time interval between the events within some observation period. It uses survival time or the hazard rate as a dependent variable. In a context of failure, the aim is to quantify the relationship between survival time and a set of explanatory variables. Survival analysis is used to study time to failure of some population. This is called the survival time. Survival analysis includes even those observations that have not failed. These are treated as censored data and an observation time can be given for censored cases indicating the last time they were observed. In the context of default prediction, survival analysis includes companies that have "defaulted" and companies that are "solvent" for the time horizon under study. Companies that have defaulted are assigned "1" status while companies that are solvent are assigned "0" status. However, there may be certain companies, who may have prepaid their debt, or paid off their debt at maturity. Such companies are said to be left-censored and are assigned status "0". There may also be some companies who would not have paid off under the 
time horizon identified for the study. These companies are said to be right censored and are also assigned the status " 0 ". Censored observations may be defined to include "event" that has not yet occurred at the end of study or time of analysis; that has withdrawn from study; or may have occurred prior to the time of event. Survival analysis technique is considered superior to other techniques due to is its ability to handle censored data.

The survival techniques are broadly as:

Life tables refers to a survival analysis technique which is non parametric and which generates time to event distributions for an entire dataset or separately for each level of a factor. The basic idea of life tables is to subdivide the period of observation into smaller time intervals. Then the probability from each of the intervals is estimated.

Kaplan-Meier Survival Analysis (KMSA) is a method of generating tables and plots of survival or hazard functions for event history data (time to event data). KMSA is a descriptive procedure for time-to-event variables for use when time is considered of essence.

The Cox regression model is a semi-parametric approach that analyses survival probabilities and failure times. The advantage of this model is that it enables the use of several explanatory variables. Cox regression maybe applied for time dependent covariates as also for time varying covariates. Cox proposed the model where different subjects have hazard functions that are proportional to one another; that is, the ratio of the hazard functions for two subjects with regression vectors $X_{1}$ and $x_{2}$ is constant over time $t i$. The general model equation is shown below:

$$
h(t \mid X)=h_{0}(t) g(X, \beta)=h_{0}(t) \exp (X \beta)
$$

where $b$ is a vector of unknown regression coefficients, and $h_{0}(t)$ is the baseline hazard, i.e. an unknown hazard function for an observation with covariate vector $Z_{0}$. Although they are always non-negative, they may be greater than one. For a small $\mathrm{D} t, h(t) \mathrm{D} t$ is the approximate probability of occurrence in the interval $(t, t 1 \mathrm{D} t)$. The survivor function $S(t)$ is the probability that failure does not occur before the time point $t$ Different survival models can be defined by assuming different relationships between the hazard rate and the explanatory variables.

\subsection{Data Source}

For the purpose of the study, secondary data has been used. The secondary data on the financial statements of the companies has been primarily collected from Prowess database of Center for Monitoring Indian Economy (CMIE) and Annual Reports of companies. The time period considered is ten years from $1^{\text {st }}$ April 2000 to $31^{\text {st }}$ March 2015. We consider this time period due to the fact that this is the most recent window and during this window we have periods of market boom, crash as well as rise. The reason for not considering the time period after that is because the research study commenced in early 2016, and the financial reports of listed companies were unavailable in the public domain during that period. The scope of this study is limited to cover listed companies in India. 
This is because, consistent with the objective of this study, publicly available and reliable information is a key determinant to a robust and parsimonious model. The data has been analyzed for listed companies in India spanning across 10 sectors.

The companies under financial distress are defined as those rated " $D$ " and under BIFR. Those companies that have entered after 2000 are included in the sample. The dependent variable here is "time" where for companies rated D and under BIFR, it takes the form of time taken to default from the time of financial year closing of 2000. The companies that survive up to end of the year 2014 are censored. Those companies which have default status are coded "1" while those companies which are solvent are coded "0". The selected sample has been subject to several trimmings of data. Since the data is taken from a broad spectrum of sectors, only those ratios which are common and are applicable to all the sectors under study have been identified. Also, the data was filtered to remove all the companies, where the covariates were not available for the years under consideration. The final sample, subject to survival analysis, represents on average 10.5 percent of firms across 10 sectors, as provided in Table 1. This classification of sectors is taken as per Prowess CMIE (Centre for Monitoring Indian Economy). As can be seen from Table 1, of the total dataset of 859 companies, 90 companies are under financial distress.

\subsection{Selection of Covariates}

\section{- Accounting ratios}

There are a vast number of financial ratios which are examined to evaluate the financial performance of corporates broadly to assess on the liquidity, solvency and profitability parameters. Thus, the research study identifies a set of 10 ratios under these three broad classifications (Table 2). The ratios chosen are based on prior works, have a bearing on the study and are easy to obtain.

Table 1. Number of companies in the dataset.

\begin{tabular}{ccccc}
\hline Sectors & $\begin{array}{c}\text { Under } \\
\text { financial distress }\end{array}$ & Solvent & Total & $\begin{array}{c}\text { \% age-under } \\
\text { financial distress/Total }\end{array}$ \\
\hline Chemicals & 20 & 182 & 202 & 9.9 \\
Construction & 3 & 48 & 51 & 5.88 \\
Consumer goods & 6 & 48 & 54 & 11.11 \\
Diversified & 3 & 33 & 36 & 8.33 \\
Food \& Agro & 9 & 76 & 85 & 10.59 \\
Machinery & 10 & 93 & 103 & 9.71 \\
Metals & 10 & 89 & 99 & 10.10 \\
Misc. & 5 & 31 & 36 & 13.89 \\
Textiles & 20 & 96 & 116 & 17.24 \\
Transport & 4 & 73 & 77 & 5.19 \\
Total & 90 & 769 & $\mathbf{8 5 9}$ & 10.48 \\
\hline
\end{tabular}

Source: Prowess CMIE, BIFR website. 
Table 2. Set of covariates used for the study.

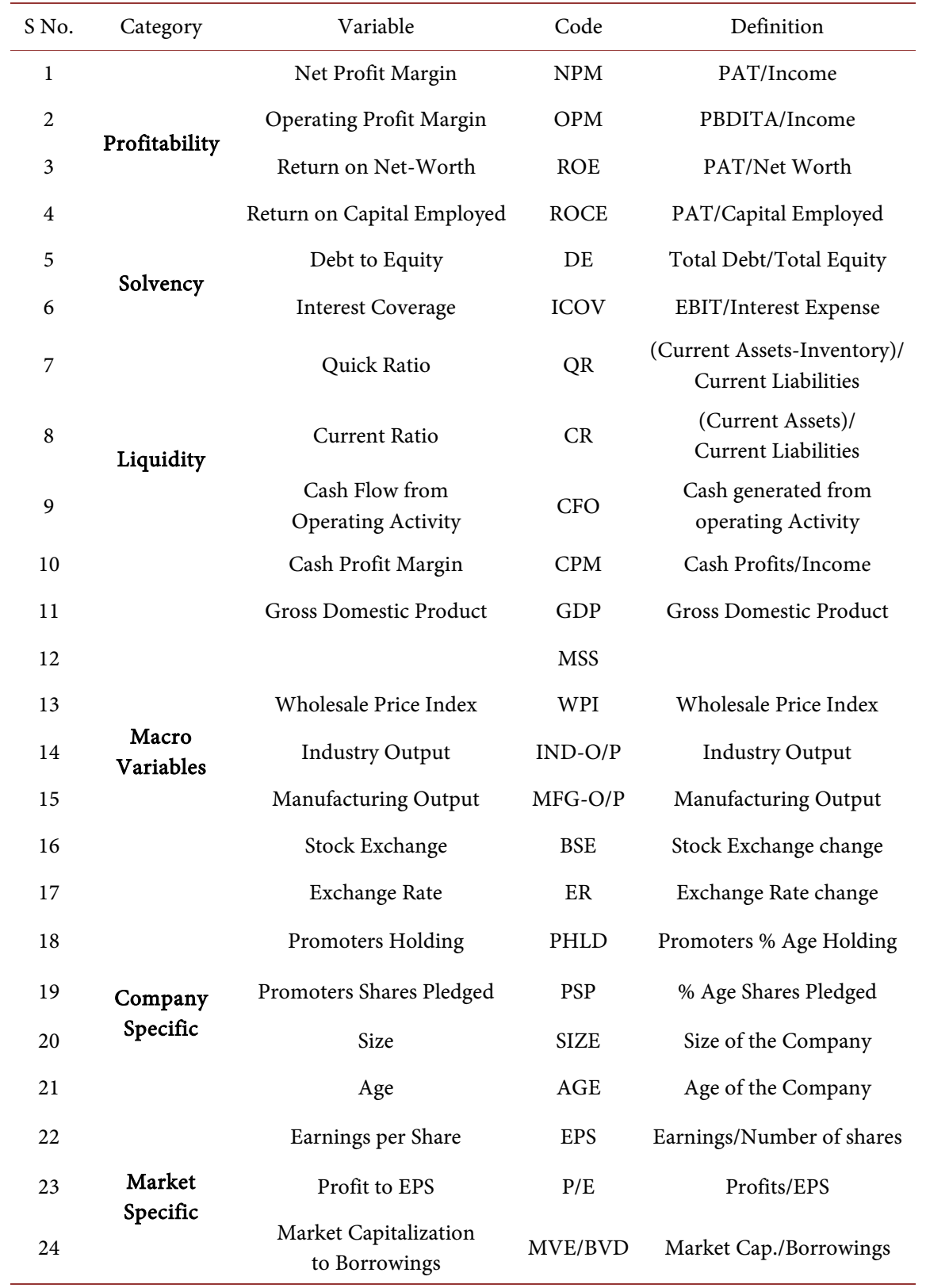

- Company specific variables are taken as AGE and SIZE.

- Macro-economic variables: The macro-economic variables identified as covariates for the study are:

1. GDP growth rate,

2. Money supply,

3. Wholesale price index,

4. Industrial output growth rate,

5. Manufacturing output growth rate,

6. Return on BSE (Bombay stock exchange),

7. Exchange rate.

- Market variables: Since the domain of study is Indian listed companies, cer- 
tain capital market ratios are also considered as earnings per share (EPS), PE ratio, beta of stock (measuring risk) and the proportion of market capitalization to debt. For market cap/ debt, those companies with mktcap/debt $>1$ are coded " 0 " and those companies with market cap/debt $<1$ are coded " 1 ".

- Ownership pattern: The identity of the shareholders can also have a significant bearing on the influence they exercise on a company's management. Conflict of interest between shareholders and management raises agency costs. However, when the shareholders are largely the management, there is strong motivation of profit maximization goals and the agency costs are low. In emerging markets and specifically in the Indian context, large family ownerships and promoters represent a substantial part of ownership. While on one hand, their main focus is on maintaining the long-term interests of the company; on the other hand, large business houses which are family-controlled firms often have expropriation concerns and may indulge in creative accounting practices. When promoter shareholding is pledged, it can prove to be a warning signal of the impending financial distress. The promoters' shareholding (\%) and the percent of promoters shares pledged are taken as two separate variables to gauge if ownership pattern plays a role in predicting default risk.

Table 2 lists the total set of explanatory variables taken for the study.

The financial ratios have been checked for multicollinearity using Pearson correlation. However, we have included all the ratios for the purpose of our analysis assuming the significance of each is somewhat different from the other.

\subsection{Descriptive Statistics}

Table 3 and Table 4 present the descriptive statistics of the explanatory variables used to estimate the Cox regression model in this paper. While Table 3 gives the descriptive statistics for companies under financial distress, Table 4 provides the descriptive statistics for solvent companies. There is significant difference in the averages for not only profit margins, but also the market ratios and the solvency ratios. It is evident from Table 3 that the mean for profit margins have negative signs, implying loss, as is also the case for interest coverage ratio which has a negative sign. The leveraging is very high as shown by the average mean which is 11 thereby implying that the companies bear a significant financial risk. EPS is also negative for these companies. It is also observed that average beta is greater than 1, indicating high risk associated with the stock beta. The promoters' ownership is less than $50 \%$ for distressed companies while for solvent companies it is more than $50 \%$. For financially distressed companies, a large chunk of promoters' shares are pledged. One significant factor which is highlighted is that for financially distressed companies, the ratio of market capitalization to total debt is much below 1 while for solvent companies, it is greater than 1 . The average age of distressed companies is not vastly different as compared to defaulted companies. However, the size of companies which are in the non-defaulted category is significantly higher as compared to defaulted companies. It is evident that larger companies have a greater risk bearing capacity. 
Table 3. Descriptive statistics for companies under default status.

\begin{tabular}{cccccc}
\hline Variable & Obs & Mean & Std. Dev. & Min & Max \\
\hline OPM & 90 & 3.938889 & 18.5486 & -54.94 & 56.31 \\
NPM & 90 & -15.1157 & 32.49218 & -221.26 & 12.3 \\
CPM & 90 & -9.97322 & 37.78827 & -311.52 & 25.35 \\
ROE & 90 & -44.7587 & 98.73102 & -642.32 & 39.97 \\
ROCE & 90 & -6.775 & 11.90366 & -38.6 & 14.76 \\
INTCOV & 90 & -1.64411 & 17.54835 & -164 & 13.68 \\
QR & 90 & 0.737578 & 0.908173 & 0.04 & 4.92 \\
CR & 90 & 1.309756 & 1.569846 & 0.27 & 10.48 \\
DE & 90 & 11.80678 & 48.58822 & 0 & 393.63 \\
Beta & 90 & 1.053111 & 0.39915 & 0 & 1.82 \\
AGE & 90 & 2.744444 & 1.294423 & 0 & 4 \\
EPS & 90 & -10.4467 & 45.80052 & -364.04 & 47.05 \\
PE & 90 & 22.83233 & 151.8597 & 0 & 1436.73 \\
PHLD & 90 & 46.18533 & 18.05288 & 0 & 87.01 \\
PSP & 90 & 37.48711 & 36.44803 & 0 & 100 \\
CFO & 90 & 98.69112 & 1495.454 & -4675.5 & 7248.5 \\
SIZE & 90 & 9976.776 & 16349.75 & 284.1 & 114743.8 \\
MVE/BVD & 90 & 0.677778 & 0.469946 & 0 & 1 \\
\hline
\end{tabular}

Source: SPSS.

Table 4. Descriptive statistics for solvent companies.

\begin{tabular}{|c|c|c|c|c|c|}
\hline Variable & Obs & Mean & Std. Dev. & Min & Max \\
\hline OPM & 769 & 14.048 & 9.478292 & -42.51 & 88.78 \\
\hline NPM & 769 & 4.681066 & 8.686087 & -115.66 & 66.06 \\
\hline CPM & 769 & 7.774473 & 7.817655 & -49.12 & 67.06 \\
\hline ROE & 769 & 16.24798 & 81.41624 & -139.25 & 2111.45 \\
\hline ROCE & 769 & 8.736359 & 12.31127 & -64.9 & 106.76 \\
\hline INTCOV & 769 & 63.08147 & 415.4726 & -44.57 & 5157.4 \\
\hline QR & 769 & 0.781211 & 0.771979 & 0.01 & 10.75 \\
\hline $\mathrm{CR}$ & 769 & 1.358993 & 0.93651 & 0.15 & 12.01 \\
\hline $\mathrm{DE}$ & 769 & 1.542987 & 7.339408 & 0 & 186.63 \\
\hline BETA & 769 & 0.873823 & 0.427962 & -0.49 & 1.79 \\
\hline AGE & 769 & 2.179454 & 1.356521 & 0 & 4 \\
\hline EPS & 769 & 14.69983 & 41.32692 & -102.81 & 790.29 \\
\hline $\mathrm{PE}$ & 769 & 19.02949 & 98.96744 & 0 & 2277.81 \\
\hline PHLD & 769 & 56.3348 & 15.45786 & 0 & 99.67 \\
\hline PSP & 769 & 8.821131 & 20.57754 & 0 & 100 \\
\hline $\mathrm{CFO}$ & 769 & 1849.778 & 11281.02 & -51655.6 & 254490 \\
\hline SIZE & 769 & 33421.98 & 173115.1 & 0 & 3143452 \\
\hline MVE/BVD & 769 & 0.494148 & 0.500291 & 0 & 1 \\
\hline
\end{tabular}

Source: SPSS. 


\subsection{Assessing the Goodness-of-Fit of the Proportional Hazard (PH) Model and the PH Assumption for Survival Models}

- Testing for proportionality assumption (PH): global test of model fit

One of the main assumptions of the Cox proportional hazard model is proportionality. We test the proportionality of the model as a whole. If the tests in the table (Table 5) are not significant ( $p$-values over 0.05 ) then we cannot reject proportionality and we assume that we do not have a violation of the proportional assumption. The global significance for our model is 0.10 , thus the proportionality assumption is met ( $p$ value $>0.05$ ). The test for proportionality assumption is done using Stata.

\section{- Goodness of fit test}

One measure of overall goodness-of-fit test is partial likelihood-ratio test. In Table 6, the output produced includes the value of -2 Log Likelihood for fitting, AIC (Akaike Information Criterion) and SBC (Schwartz Bayesian Criterion) for fitting a model without covariance and fitting a model with covariates. Akaike introduced the concept of the information criteria as a tool optimal model selection. Schwartz is derived from a Bayesian modification of the AIC criterion to develop a SBC model.

The likelihood ratio test has been used to see the variables included in the final model are significant in explaining some of variability in data. The ChiSquare statistic is the difference in $-2 \log$ Likelihood ( $-2 \mathrm{LL}$ ) between the final model and a reduced model. The null hypothesis is that all parameters $(k \beta 1$, $\beta 2 \ldots, \beta \mathrm{k})$ of the effect are 0 . The statistic quantity of the aforesaid hypothesis testing is $-2 \log$ Likelihood $(=-2 \log (\mathrm{L}(0)-\mathrm{L}(\beta))$ which observes $\lambda 2(k)$, where $\mathrm{L}(0)$ is the likelihood function value under the null hypothesis, while $\mathrm{L}(\beta)$ is the likelihood function value in consideration of the whole model. The Chi-Square is the difference between (1196.5298 - 963.764) rejects the null hypothesis and confirms the significance of adding predictors to the model (Table 7).

\subsection{Model Validity}

Model validity is assessed using the concordance index in survival analysis technique. The index of concordance is a "global" index for validating the predictive

Table 5. Test of proportional hazard assumption.

\begin{tabular}{cccc}
\hline & chi2 & df & Prob > chi2 \\
\hline global test & 47.89 & 26 & 0.10 \\
\hline
\end{tabular}

Source: Stata.

Table 6. Goodness of fit test the PHREG procedure model fit statistics.

\begin{tabular}{ccc}
\hline Criterion & Without Covariates & With Covariates \\
\hline-2 Log L & 1196.530 & 963.7642 \\
AIC & 1196.530 & 1015.764 \\
SBC & 1196.530 & 1139.414 \\
\hline
\end{tabular}

Source: Stata. 
Table 7. Empirical findings on the Cox regression.

\begin{tabular}{|c|c|c|c|c|c|c|c|c|c|}
\hline \multirow[b]{2}{*}{ Variable } & \multicolumn{3}{|c|}{ Model I } & \multicolumn{3}{|c|}{ Model II } & \multicolumn{3}{|c|}{ Model III } \\
\hline & $\begin{array}{c}\text { Co-efficient } \\
\text { B }\end{array}$ & $\begin{array}{c}\text { Wald } \\
\text { statistics }\end{array}$ & $\begin{array}{l}\text { Exp (B) } \\
\text { Hazard } \\
\text { ratio }\end{array}$ & $\begin{array}{c}\text { Co-efficient } \\
\text { B }\end{array}$ & $\begin{array}{c}\text { Wald } \\
\text { statistics }\end{array}$ & $\begin{array}{c}\text { Exp (B) } \\
\text { Hazard } \\
\text { ratio }\end{array}$ & Co-efficient & $\begin{array}{c}\text { Wald } \\
\text { statistics }\end{array}$ & $\begin{array}{c}\text { Exp (B) } \\
\text { Hazard } \\
\text { ratio }\end{array}$ \\
\hline $\mathrm{PAT} / \mathrm{NW}$ & -0.0037975 & $-4.19^{* * \star}$ & 0.9962097 & & & & & & \\
\hline $\mathrm{PAT} / \mathrm{CE}$ & -0.0563988 & $-5.95^{\star * \star}$ & 0.9451621 & & & & & & \\
\hline INTCOV & -0.0108472 & $-2.22^{\star *}$ & 0.9892115 & & & & & & \\
\hline $\mathrm{DE}$ & 0.0038621 & $1.94^{* *}$ & 1.00387 & & & & & & \\
\hline AGE & 0.1722198 & $1.96^{\star *}$ & 1.187939 & & & & & & \\
\hline GDPGR & & & & 0.3498395 & $6.98^{\star * *}$ & 1.41884 & & & \\
\hline BSE return & & & & -4.056658 & $-1.96^{\star \star}$ & 0.0173068 & & & \\
\hline ER & & & & 4.926206 & $1.88^{*}$ & 137.8555 & & & \\
\hline BETA & & & & & & & 0.8467657 & $2.92^{\star * *}$ & 2.332092 \\
\hline EPS & & & & & & & -0.0090507 & $-6.24^{\star * \star}$ & 0.9909902 \\
\hline MKTCAP/DEBT & & & & & & & 0.5254038 & $2.28^{\star *}$ & 1.691142 \\
\hline$-2 L L(b=0)$ & 1196.530 & & & 1196.530 & & 1196.530 & & & \\
\hline$-2 L L$ & 1065.635 & & & 1154.195 & & 1151.457 & & & \\
\hline Prob $>$ chi $2=$ & 0.0000 & & & & & 0.0000 & & & 0.0000 \\
\hline
\end{tabular}

Source: Stata. ${ }^{*}$ significance at $10 \%$; ${ }^{* *}$ significance at $5 \%$; ${ }^{* * *}$ significance at $1 \%$.

ability of a survival model. The concordance index (CI) or c-index can be interpreted as the fraction of all pairs of subjects whose predicted survival times are correctly ordered among all subjects that can actually be ordered. In other words, it is the probability of concordance between the predicted and the observed survival (Newson, 2010). This index is a generalization of the WilcoxonMann-Whitney statistics and thus of the area under the ROC curve (AUC) to regression problems in that it can be applied to continuous output variables and also account for censoring of the data. Like for the AUC, $c=1$ indicates perfect prediction accuracy and $c=0.5$ is as good as a random predictor. High values mean that the model predicts higher probabilities of survival for higher observed survival times.

The predictive ability of the models is also tested by plotting the Receiver Operating Characteristics (ROC) curve. The ROC curve quantifies the accuracy of diagnostic tests to discriminate between defaulted firms and solvent firms using each value of the score as a possible cutoff point. The analysis uses the ROC curves of the sensitivity (percentage of true defaulted outcomes correctly specified) vs. 1-specificity (percentage of false defaulted outcomes correctly specified) of the diagnostic test. This calculates the area under the ROC curve. The area under the ROC curve (herein referred to as AUC) measures the model's performance in predicting actual defaults. The ROC reports the percentage of defaults that the model correctly classified as defaults on the y-axis and the percentage of 
non-defaults that the model incorrectly classified as defaults on the $\mathrm{x}$-axis. The advantage of the ROC curve resides in its ability to account for Type II errors.

\subsection{KMV Model to Estimate PD and Identify Key Predictors}

KMV Corporation, a firm specialized in credit risk analysis developed a credit risk methodology, as well as an extensive database, to assess default probabilities and the loss distribution related to both default and migration risks. The KMVMerton model applies the framework of Merton (1974), which is a market-based model and is a direct application of the Black Scholes Model.

In the model, the value of equity $V_{E}$, the volatility of equity $\sigma_{E}$ and several other observable variables are applied by solving two nonlinear simultaneous equations.

$$
\begin{gathered}
V_{E}=V_{A} \Phi\left(d_{1}\right)-D e^{-r T} \Phi\left(d_{2}\right) \\
\sigma_{E}=\frac{V_{A}}{V_{E}} \Phi\left(d_{1}\right) \sigma_{A}
\end{gathered}
$$

where $V_{E}$ is equivalent to a call option written on the underlying, that is the firms' asset value $V_{A}, \mu_{E}$ is the expected continuously compounded return on equity and $\sigma_{E}$ is the equity volatility. The KMV-Merton model basically uses these two nonlinear Equations (1) and (2), to translate the value and volatility of a firm's equity into an implied probability of default. The author developed an algorithm for solving Equations (1) and (2) and thereby determining PD (Gupta et al. 2013). After inferring these values, the model specifies that the probability of default is the normal cumulative density function of a $z$-score depending on the firm's underlying value, the firm's volatility, and the face value of the firm's debt.

Once the probability of default is computed by the KMV model, in the first stage of analysis, regression is run with this $\mathrm{PD}$ as the dependent variable and the set of covariates (Table 2) as the predictors of default. These variables, once identified can be used as key predictors of default. As such, it provides a simple and robust measure of default risk.

\section{Empirical Findings}

\subsection{Results from Cox Regression}

The Cox Regression procedure is useful for modeling the time to a specified event based upon the values of given covariates. Cox regression (or proportional hazards regression) method enables investigating the effect of several variables upon the time a specified event takes to happen. The key statistical output is the hazard ratio. Data contain censored and uncensored cases. Though similar to logistic regression, but Cox regression assesses relationship between survival time and covariates. For the purpose of analyzing the impact of covariates, the dependent variable is the "time to default", with companies under default having status " 1 " and companies which are solvent coded as "0". The output from Cox regression is generated using Stata. 
" $\mathrm{B}$ " in the output table is the regression coefficient, Wald is the test statistics, and EXP (B) is the hazard ratio. The hazard ratio is the predicted change in the hazard for a unit increase in the predictor. The likelihood chi-square statistic is calculated by comparing the deviance $(-2 *$ Log Likelihood) of the model with all of the covariates, against the model with no covariates. The difference is then tested against a chi-square distribution with degrees of freedom equal to the difference between the degrees of freedom of the old and new models. The null hypothesis is that all parameters of covariates to the model can be assessed from the significance test given with each coefficient in the main output. A hazard is the rate at which events happen, so that the probability of an event happening in a short time interval is the length of time multiplied by the hazard. HR represents the incremental increase in hazard per unit increase in predictor variable. A value of $<1$ says that an increase in one unit for that particular variable, will decrease the probability of experiencing an end point throughout the observation period. A hazard ratio of one means that the variable is having no impact on the survival. A hazard ratio greater than one indicates more rapid hazard timing and less than 1 would imply slower impact.

The Wald test is $\frac{\text { coeff }}{\text { std.err (coeff })} \sim N(0,1)$. This Wald statistic has a chi-square distribution with one degree of freedom under the null hypothesis.

The empirical findings have been presented in five different models. Model I is based on findings by including accounting ratios only as the independent variables. It can be seen from Table 7 that Return on Equity, Return on Capital Employed, Interest coverage and Debt to Equity ratio are all statistically significant. These ratios are thus the early warning predictors. While the first column shows the coefficient, the third column shows the hazard ratio corresponding to each variable. The coefficients of ROE, ROCE and INTCOV are showing negative signs indicating that an increase in either covariate decreases the hazard of entering into financial distress. The hazard ratio for all these three variables shows that an increase of one unit in ROE, ROCE and INTCOV implies 0.99, 0.94 and 0.98 decrease in financial distress risk. It can also be seen that for Debt/ Equity and Age as variables, the hazard ratio is just about 1 implying a negligible impact of these variables on financial risk. Model II shows the findings taken from macro-economic variables only. It can be seen that GDP growth rate, BSE stock returns and exchange rate emerge as statistically significant variables. The hazard ratio for GDP growth rate and exchange rate is greater than 1 implying these variables speed the time to failure. Model III identifies the statistically significant market-driven variables, namely, EPS, beta of stock and the ratio of market value of firm to book value of outstanding debt. These ratios are significant for listed firms. It is observed that coefficient of EPS is negative implying an increase in one unit of the variable decreases the financial distress of the firms. The hazard ratio for beta and MVE/BVD are greater than 1 showing higher rate of failure for every one unit increase in these two variables.

Model IV factors the impact of ownership patterns on the default risk of 
firms. Both the variables: promoters' ownership and percent of promoters shares pledged are statistically significant at $1 \%$. The sign of coefficient for promoters' percent holding is negative implying as there is an increase in promoters shareholding, it reduces the risk of financial distress. This also highlights that in Indian context, family groups where bulk ownership is with promoters and families would be lesser liable to default. Although promoters shares pledged is a statistically significant variable, the hazard ratio is virtually 1 signifying no impact on financial distress. It was observed from the descriptive statistics that the average percent of shares pledged was much higher for companies under default than companies that are solvent. Model V factors all variables together. It is seen that ROE, ROCE are significant predictors while among macro variables, change in money supply and inflation rate have a significant bearing on financial distress.

The empirical findings clearly show that profitability, solvency and liquidity play an important role in assessing the credit worthiness of a firm. It is also observed that when macro-economic variables (MV) are added, exchange rate, stock index and GDP growth rate are significant predictors.

The inclusion of MVs could also prove useful in anticipating the volatility of a company's probability of default (PD) to changes in economic conditions in the future and therefore could help give a further insight into risk when assessing default risk. It is also to be seen that higher promoter stake reduces the risk of companies entering into default. In emerging markets and specifically in the Indian context, large family ownerships and promoters represent a substantial part of ownership. Thus, when the shareholders are largely the management, there is strong motivation of profit maximization goals and the agency costs are low. From the empirical findings based on market variables, it can be seen that those companies whose market capitalization is lower than the book value of debt are largely the defaulted firms with beta $>1$ in majority of cases.

\subsection{Kaplan Meier}

The Kaplan-Meier procedure is a method of estimating time-to-event models in the presence of censored cases. It can compare the distribution by levels of a factor variable or produce separate analyses by levels of a stratification variable. The assumptions for Kaplan Meier estimates are that probabilities for the event of interest should depend only on time after the initial event without covariates effects.

Survivor function, $S(t)$ defines the probability of surviving longer than time $t$. This is shown in the Kaplan-Meier curves. Hazard function is the derivative of the survivor function over time $h(t)=\mathrm{d} S(t) / \mathrm{d} t$ instantaneous risk of event at time $t$. conditional failure rate (Figure 1 ). The figure suggests that the probability of financial survival is stable in the initial years and tends to drop only after 10 years, after which survival is declining or failure rate increasing. The graphical examination of the survival graph indicates that the steep increase in defaults occur after the first 10 years of the study, 61 companies defaulted after first 10 


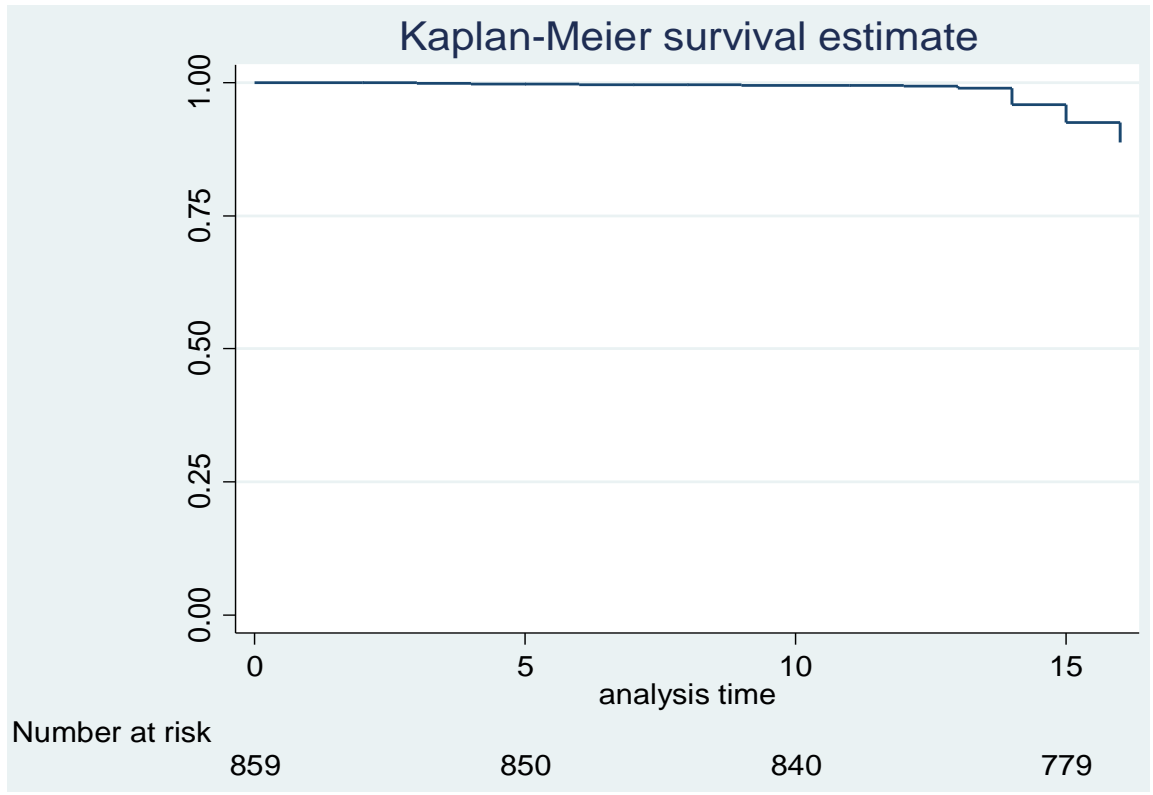

Figure 1. Kaplan Meier survival curve.

years. The graph is parallel to $\mathrm{x}$-axis during the first 10 years showing high survival times.

From Figure 2 and Table 8 attached, it can be seen that the Auto sector (Transport) and the Miscellaneous sector show the least defaults, while the Chemicals, Textiles and Metals sectors have shown the sharpest decline in survival rate or a higher number of companies defaulting. The K-M graphs enable us to analyze different sectors in terms of the defaults over different time horizons.

\subsection{Model Validity}

The index of concordance is a "global" index for validating the predictive ability of a survival model. An index between 0.5 and 1 demonstrates good ability of the model, here the concordance index is 0.918 thus exhibiting high predictive power.

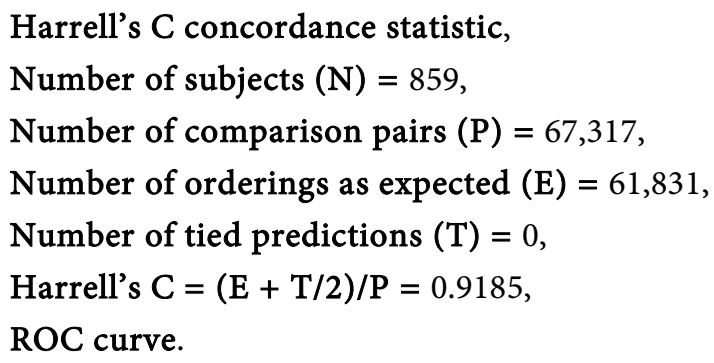

The area under the ROC curve (herein referred to as AUC) measures the model's performance in predicting actual defaults. The ROC reports the percentage of defaults that the model correctly classified as defaults on the y-axis and the percentage of non-defaults that the model incorrectly classified as defaults on the $\mathrm{x}$-axis. The predictive ability of our model is good as shown in the area under ROC (AUC) which is $81.9 \%$ (Figure 3). 


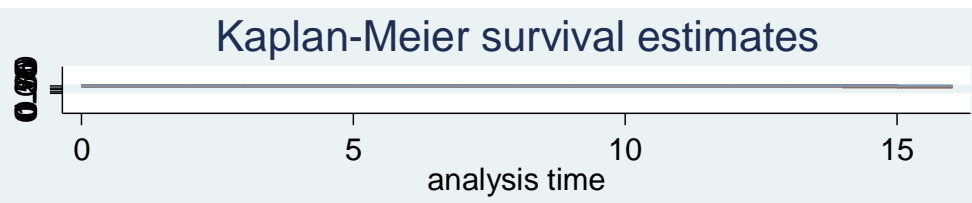

\section{4}

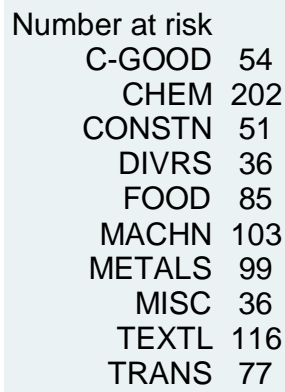

198

50

36

85

101

99

36

116

75

54

196

50

35

85

97

98

35

116

74

\begin{tabular}{|ll|}
\hline C-GOOD & CHEM \\
CONSTN & DIVRS \\
FOOD & MACHN \\
METALS & MISC \\
TEXTL & TRANS \\
\hline
\end{tabular}

Figure 2. Kaplan Meier sector-wise survival estimates.

Area under ROC

Area

0.819

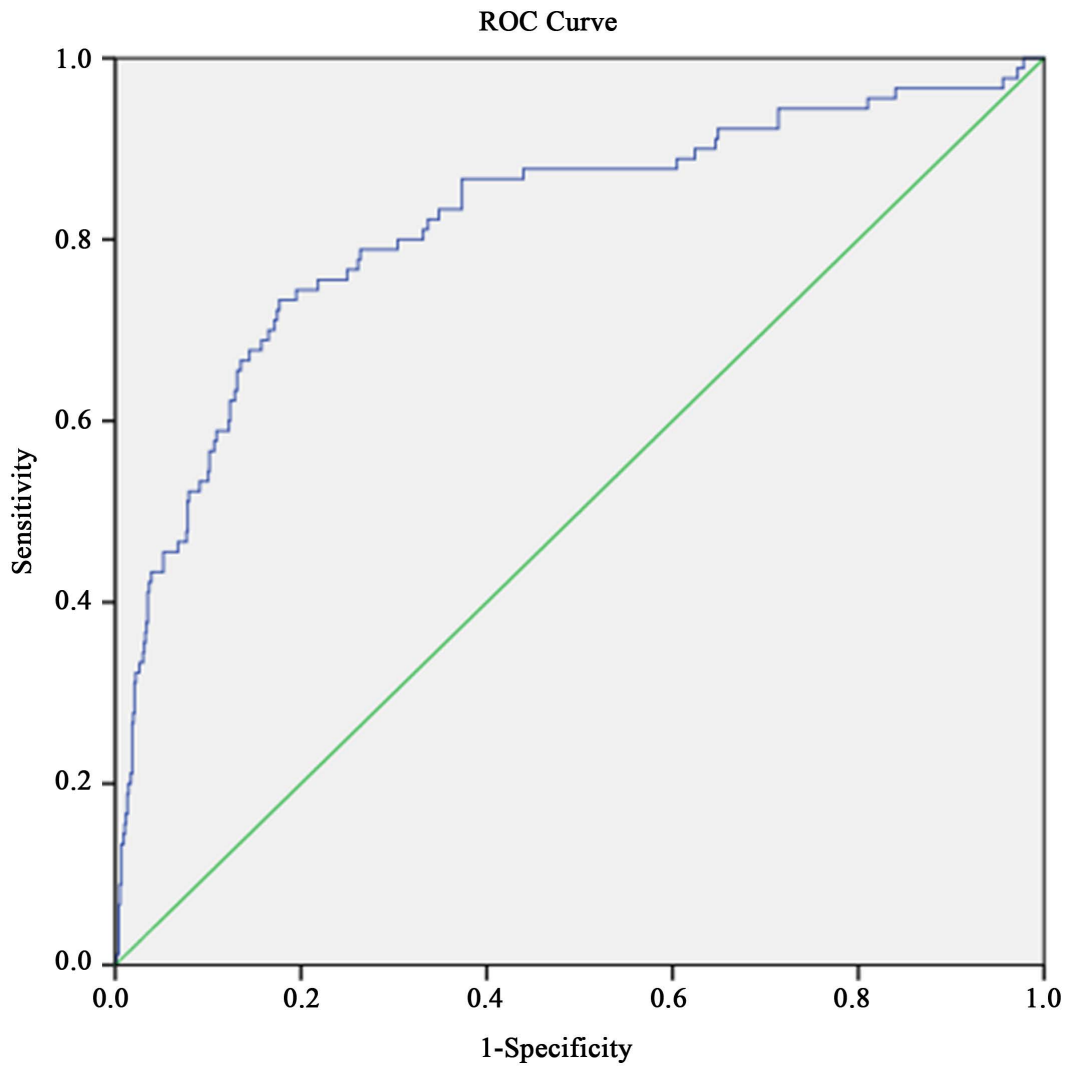

Figure 3. Receiver Operating Characteristic curve (ROC curve) for Cox regression. 
Table 8. Empirical findings on Cox regression.

\begin{tabular}{|c|c|c|c|c|c|c|}
\hline \multirow[b]{2}{*}{ Variable } & \multicolumn{3}{|c|}{ Model IV } & \multicolumn{3}{|c|}{ Model V } \\
\hline & $\begin{array}{c}\text { Co-efficient } \\
\text { B }\end{array}$ & $\begin{array}{c}\text { Wald } \\
\text { statistics }\end{array}$ & $\begin{array}{c}\text { Exp (B) } \\
\text { Hazard ratio }\end{array}$ & $\begin{array}{c}\text { Co-efficient } \\
\text { B }\end{array}$ & $\begin{array}{c}\text { Wald } \\
\text { statistics }\end{array}$ & $\begin{array}{c}\text { Exp (B) } \\
\text { Hazard ratio }\end{array}$ \\
\hline PHLD & -0.0197924 & $-3.21^{\star * *}$ & 0.9804022 & -0.0224032 & $-3.11^{\star * *}$ & 0.9778459 \\
\hline PSP & 0.0225452 & $7.70^{* * *}$ & 1.022801 & 0.0144532 & $4.22^{\star * \star}$ & 1.014558 \\
\hline ROE & & & & -0.0033582 & $-3.24^{\star * *}$ & 0.9966474 \\
\hline ROCE & & & & -0.0519902 & $-4.30^{* * *}$ & 0.9493382 \\
\hline INTCOV & & & & -0.010842 & $0.002^{\star \star}$ & 0.9892165 \\
\hline MSS & & & & 0.229 & $7.059^{* * *}$ & 1.257 \\
\hline WPI & & & & 0.472 & $10.865^{\star * *}$ & 1.603 \\
\hline$-2 L L(b=0)$ & 1196.530 & & & 1196.530 & & \\
\hline$-2 L L$ & 1113.922 & & & 963.764 & & \\
\hline Prob $>$ chi $2=$ & 0.0000 & & & & & 0.0000 \\
\hline
\end{tabular}

Source: Stata. ${ }^{*}$ significance at $10 \% ;{ }^{* *}$ significance at $5 \%$; ${ }^{* *}$ significance at $1 \%$.

\subsection{KMV Model}

\section{- Structural Model-Using KMV to Estimate PD}

The KMV model as explained in Section III of the research paper is applied to determine the continuous valuations of probability of default (PD).

It can be seen from the table above (Table 9) that the probability of default generated from the structural KMV model, is used as the dependent variable and the independent variables (Table 2) are used and multiple regression is run to determine the key predictors. Similar to our previous findings, Model I is with only financial ratios and it can be seen that operating profit margins, return on net worth (ROE), return on capital employed (ROCE), quick ratio are all significant drivers of default risk. In Model II all three macro-economic variables: GDP growth rate, BSE stock returns and exchange rate are statistically significant. Similarly Model III shows that both promoters' ownership and promoters' shares pledged have an important bearing on financial distress. It can also be observed that the profitability ratios (OPM, ROE and ROCE) have negative coefficients thus showing that increased profitability reduces financial distress. Quick ratio reflects liquidity of companies and an increase in liquidity and thereby quick ratio reduces financial distress. Promoters' shareholding also has a negative coefficient thus showing that higher promoters' stake reduces probability of default.

On comparing the results based on Cox regression (survival analysis) with multiple regression using KMV model, reinforces the fact that liquidity and profitability have a significant role to play in determining financial distress risk. Also, macro-economic variables do have a bearing on default prediction.

\section{Conclusions}

This research study has been undertaken with the objective of combining financial 
Table 9. Empirical Findings on KMV model using multiple regression.

\begin{tabular}{|c|c|c|c|c|c|c|c|c|}
\hline \multirow{2}{*}{ Variable } & \multicolumn{2}{|c|}{ Model I } & \multicolumn{2}{|c|}{ Model II } & \multicolumn{2}{|c|}{ Model III } & \multicolumn{2}{|c|}{ Model IV } \\
\hline & Co-efficient B & T-statistics & Co-efficient B & T-statistics & Co efficient & T-statistics & Co-efficient & T-statistics \\
\hline OPM & 0.0024101 & $2.39^{\star * *}$ & & & & & 0.0020056 & $2.05^{\star *}$ \\
\hline CPM & -0.0025554 & $-3.75^{\star * \star}$ & & & & & & \\
\hline ROE & -0.0004191 & $-2.80^{\star \star}$ & & & & & -0.0004171 & $-2.19^{\star * *}$ \\
\hline ROCE & -0.0029711 & $-3.17^{\star \star}$ & & & & & -0.0017941 & $-1.87^{*}$ \\
\hline QR & -0.0540287 & $-2.25^{\star *}$ & & & & & -0.0545645 & $-2.32^{\star * *}$ \\
\hline AGE GROUP & 0.0124169 & $2.09^{* *}$ & & & & & & \\
\hline GDPGR & & & 0.0246896 & $4.07^{\star * *}$ & & & 0.0235659 & $1.92^{*}$ \\
\hline BSE return & & & -0.4044813 & $-2.72^{\star \star *}$ & & & -0.3758394 & $-1.80^{\star}$ \\
\hline ER & & & -0.3636214 & $-1.76^{* * *}$ & & & & \\
\hline PHLD & & & & & -0.0010679 & $-2.09^{* *}$ & -0.0009722 & $-1.93^{* *}$ \\
\hline PSP & & & & & 0.0027229 & $8.09^{* * *}$ & 0.0019181 & $5.55^{\star * *}$ \\
\hline
\end{tabular}

Source: Stata. ${ }^{*}$ significance at $10 \% ;{ }^{* *}$ significance at $5 \% ;{ }^{* *}$ significance at $1 \%$.

variables, macro-economic factors, and ownership structure along with marketbased default drivers to predict corporate default. Specifically, this research highlights the impact of multiple covariates on time to default. For this purpose, the semi-parametric Cox proportional hazard model is applied on a dataset of Indian listed companies. The research findings substantiate the significance of financial parameters as profitability, solvency and liquidity being essential in sound financial health of corporates. The author extended prior works on KMV model to highlight the common drivers or predictors of financial distress eventually leading to default. These predictors can be used as robust early warning indicators of firm failure in India. Moreover, these parameters can be used to assess the likelihood of default by a company in the event of information not being available as in case of firms that are not listed.

Survival analysis is identified as the tool for analysis, as unlike traditional models of bankruptcy prediction, it considers "time to default" as the integral factor. Survival analysis can provide improvements in long term forecasting relative to simple cross-sectional methods. When the objective is to preempt financial distress, time to default is a critical factor. The uniqueness of survival analysis is in its ability to handle censoring data in practical business situations. It is considered superior to other models (DA, logit) as it is not only able to account for censoring, but can compare survival between $2+$ groups and assess relationship between covariates and survival time. Moreover, these models are unable to handle a continuous dependent variable such as time to default. Survival analysis provides a consistent means of predicting probability of default within many different periods of time. It also has an inherent mechanism for factoring in the most recent data into the model. Survival analysis modeling gives more valuable information, such as a whole predicted survival function, rather than a single pre- 
dicted survival probability. In practice, this model can be used for credit risk evaluation and modeling by incorporating forecasts of macroeconomic conditions into the assessment of applications. Survival probability can forewarn lenders on the creditworthiness of the firm, the analysis can be used effectively in retaining existing firms, and acquiring new ones in different industries and in structuring their repayment structure based on survival times.

The present study has some limitations which can be the scope for future research. First the analysis is restricted to Cox model that is based on proportional hazard assumption. Although valid, the research can be extended to examine other forms of survival analysis techniques. Secondly, other variables can be incorporated which can be more insights into factors impacting distress risk. The data can be tested by being lagged by 1 -year, 5 -year to examine the impact on default predictors. Moreover, distress risk identified here is based on ratings of companies; the definition of default can be broadened to include bankruptcy, restructuring, and others. The model has scope for further research by including time varying covariates into the model; considering the impact of specific factors on the survival probabilities and doing extensive research on the non-parametric techniques of Life Tables and Kaplan Meier.

\section{Support}

The infrastructural and financial support provided by FORE School of Management, New Delhi in completing this research is gratefully appreciated.

\section{References}

[1] Gupta, V., Mittal, R.K. and Bhalla, V.K. (2013) Estimating the Default Risk of Public Limited Companies in India Using Structural KMV Model. Prajnan, 41, 283-311.

[2] Beaver, W.H. (1966) Financial Ratios as Predictors of Failure. Journal of Accounting Research, 4, 71-111. https://doi.org/10.2307/2490171

Beaver, W.H. (1968) Alternative Accounting Measures as Predictors of Failure, Financial Ratios as Predictors of Failure. Journal of Accounting Research, 43, 113 122. http://www.jstor.org/stable/244122

[3] Altman, E. (1968) Financial Ratios, Discriminant Analysis and the Prediction of Corporate Bankruptcy. Journal of Finance, 23, 589-609.

[4] Ohlson, J.A. (1980) Financial Ratios and the Probabilistic Prediction of Bankruptcy. Journal of Accounting Research, 18, 109-131. https://doi.org/10.2307/2490395

[5] Zmijewski, M.E. (1984) Methodological Issues Related to Estimation of Financial Distress Prediction Models. Journal of Accounting Research, 22, 59-82. https://doi.org/10.2307/2490859

[6] Merton, R.C. (1974) On the Pricing of Corporate Debt: The Risk Structure of Interest Rates. Journal of Finance, 29, 449-470. https://doi.org/10.1111/j.1540-6261.1974.tb03058.x

[7] KMV (2003) Credit Monitor Overview. Mimeo K, CAMV Corporation, San Francisco.

[8] Black, F. and Cox, J. (1976) Valuing Corporate Securities: Some Effects of Bond Indenture Provisions. Journal of Finance, 31, 351-367. https://doi.org/10.1111/j.1540-6261.1976.tb01891.x 
[9] Longstaff, F. and Schwartz (1995) A Simple Approach to Valuing Risky Fixed and Floating Rate Debt. Journal of Finance, 50, 789-819. https://doi.org/10.1111/j.1540-6261.1995.tb04037.x

[10] Brockman, P and Turtle, H.J. (2003) A Barrier Option Framework for Corporate Security Valuation. Journal of Financial Economics, 67, 511-529. https://doi.org/10.1016/S0304-405X(02)00260-X

[11] Bandyopadhyay, A. (2007) Mapping Corporate Drift towards Default: Part 1: A Market-Based Approach. Journal of Risk Finance, 8, 35-45. https://doi.org/10.1108/15265940710721064

Bandopadhyay, A. (2007) Mapping Corporate Drift towards Default: Part 2: A Hybrid Credit-Scoring Model. Journal of Risk Finance, 8, 46-55. https://doi.org/10.1108/15265940710721073

[12] Baninoe, R. (2010) Corporate Bankruptcy Prediction and Equity Returns in the U.K. Cranfield School of Management, Cranfield University, Oxfordshire.

[13] Laitinen, E.K. (2005) Survival Analysis and Financial Distress Prediction: Finnish Evidence. Review of Accounting \& Finance, 4, 76-90. https://doi.org/10.1108/eb043438

[14] Trujillo-Ponce, A., Samaniego-Medina, R. and Cardone-Riportella, C. (2012) Examining What Best Explains Corporate Credit Risk: Accounting-Based versus Market-Based Models. Journal of Business Economics and Management, 15, 253-276.

[15] Kumar, R.G. and Kumar, K. (2012) A Comparison of Bankruptcy Models. International Journal of Marketing, Financial Services and Management Research, 1, 76-86.

[16] Jensen, M. and Meckling, W. (1976) Theory of the Firm and Managerial Behavior, Agency Cost and Ownership Structure. Journal of Financial Economics, 3, 305-360. https://doi.org/10.1016/0304-405X(76)90026-X

[17] Shleifer, A. and Vishny, R. (1986) Large Shareholders and Corporate Control. Journal of Political Economy, 94, 461-488. https://doi.org/10.1086/261385

Shleifer, A. and Vishny, R. (1997) A Survey of Corporate Governance. Journal of Finance, 52, 737-783.

[18] Xu, X. and Wang, Y. (1997) Ownership Structure, Corporate Governance, and Corporate Performance: The Case of Chinese Stock Companies. Policy Research Working Paper 1794, The World Bank, Washington DC.

[19] Cox, D.R. (1972) Regression and Life Tables. Journal of the Royal Statistical Society, 34, 187-220.

[20] Breslow, N.E. (1974) Covariance Analysis of Censored Survival Data. Persistent Link Biometrics, 30, 89-99. https://doi.org/10.2307/2529620

[21] Cox, D.R. 1975) Partial Likelihood. Biometrika, 62, 269-276. https://doi.org/10.1093/biomet/62.2.269

[22] Efron, B. (1977) The Efficiency of Cox's Likelihood Function for Censored Data. Journal of American Statistical Association, 72, 557-565. https://doi.org/10.1080/01621459.1977.10480613

[23] Narain, B. (1992) Survival Analysis and the Credit Granting Decision. In: Thomas, L.C., Crook, J.N. and Edelman, D.B., Eds., Credit Scoring and Credit Control, OUP, Oxford, 109-121.

[24] Thomas, L.C., Banasik, J. and Crook, J.N. (1999) Not If but When Loans Default. Journal of Operational Research Society, 50, 1185-1190. https://doi.org/10.1057/palgrave.jors.2600851

[25] Lando, D. (1994) On Cox Processes and Credit Risky Bonds. Review of Derivatives Research, 22, 99-120; PhD Thesis, Cornell University, Ithaca, NY. 
[26] Harrell, J.F.E. (2002) Regression Modeling Strategies: With the Applications to Linear Models, Logistic Regression, and Survival Analysis. Springer, New York.

[27] Stepanova, M. and Thomas, L. (2000) Survival Analysis Methods for Personal Loan Data. Operations Research, 50, 277-289. https://doi.org/10.1287/opre.50.2.277.426

[28] Chava, S. and Jarrow, R. (2004) Bankruptcy Prediction with Industry Effects. Review of Finance, 8, 537-569. https://doi.org/10.1093/rof/8.4.537

[29] Laitinen, E.K. (2010) Financial and Non-Financial Variables in Predicting Failure of Small Business Reorganization: Comparison of Logistic Regression Analysis and Survival Analysis. International Journal of Accounting and Finance, 4, 1-34. https://doi.org/10.1504/IJAF.2013.053111

[30] Hou, O.Y. and Chuang, S.S. (2007) Examining Financially Distressed Companies in Taiwan: Application of Survival Analysis. The Business Review, 8, 231-242.

[31] Duffie, D., Saita, L. and Wang, K. (2007) Multi-Period Corporate Default Prediction with Stochastic Covariates. Journal of Financial Economics, 83, 635-665. https://doi.org/10.1016/j.jfineco.2005.10.011

[32] Bellotti, T. and Crook, J. (2008) Credit Scoring with Macroeconomic Variables Using Survival Analysis. Journal of the Operational Research Society, 60, 1699-1707.

[33] Lee, M.C. (2014) Business Bankruptcy Prediction Based on Survival Analysis Approach. International Journal of Computer Science \& Information Technology, 6, 103-119.

[34] Rommer, A.D. (2005) A Comparative Analysis of Determinants of Financial Distress in French, Italian and Spanish Firms. Denmark National Bank Working Paper, University of Copenhagen, Copenhagen. www.nationalbanken.dk/en/publications/Documents/2005/05/wp26_samlet.pdf

[35] Chancharat, N., Davy, P., McCrae, M. and Tian, G. (2010) Multiple States of Financially Distressed Companies: Tests Using a Competing-Risks Model. Australasian Accounting Business and Finance, 4, 27-44.

[36] Kim, M.H. and Partington, G. (2008) The Dynamic Prediction of Company Failure. The 21 st Australasian Finance and Banking Conference, Sydney, 41-77.

[37] Nieddu, L. and Vitiello, C. (2013) Determinants of the Duration of Contracts: A Longitudinal Study in the Italian Fishery Sector. Italian Review of Economics, Demography and Statistics, 67, 135-142.

\section{Submit or recommend next manuscript to SCIRP and we will provide best service for you:}

Accepting pre-submission inquiries through Email, Facebook, LinkedIn, Twitter, etc. A wide selection of journals (inclusive of 9 subjects, more than 200 journals)

Providing 24-hour high-quality service

User-friendly online submission system

Fair and swift peer-review system

Efficient typesetting and proofreading procedure

Display of the result of downloads and visits, as well as the number of cited articles

Maximum dissemination of your research work

Submit your manuscript at: http://papersubmission.scirp.org/

Or contact tel@scirp.org 